\title{
PAPER
}

\section{Sensitivity of clinical and behavioural tests of spatial neglect after right hemisphere stroke}

\begin{abstract}
P Azouvi, C Samuel, A Louis-Dreyfus, T Bernati, P Bartolomeo, J-M Beis, S Chokron, M Leclercq, F Marchal, Y Martin, G de Montety, S Olivier, D Perennou, P Pradat-Diehl, C Prairial, G Rode, E Siéroff, L Wiart, M Rousseaux, for the French Collaborative Study Group on Assessment of Unilateral Neglect (GEREN/GRECO)
\end{abstract}

J Neurol Neurosurg Psychiatry 2002;73:160-166

See end of article for authors' affiliations

Correspondence to: Dr P Azouvi, Service de Rééducation Neurologique, Hôpital Raymond Poincaré, 92380 Garches, France; philippe.azouvi@ rpc.ap-hop-paris.fr

Received

19 November 2001

In revised form

19 April 2002

Accepted 30 April 2002
Objectives: The lack of agreement regarding assessment methods is responsible for the variability in the reported rate of occurrence of spatial neglect after stroke. The aim of this study was to assess the sensitivity of different tests of neglect after right hemisphere stroke.

Methods: Two hundred and six subacute right hemisphere stroke patients were given a test battery including a preliminary assessment of anosognosia and of visual extinction, a clinical assessment of gaze orientation and of personal neglect, and paper and pencil tests of spatial neglect in the peripersonal space. Patients were compared with a previously reported control group. A subgroup of patients $(n=69)$ received a behavioural assessment of neglect in daily life situations.

Results: The most sensitive paper and pencil measure was the starting point in the cancellation task. The whole battery was more sensitive than any single test alone. About $85 \%$ of patients presented some degree of neglect on at least one measure. An important finding was that behavioural assessment of neglect in daily life was more sensitive than any other single measure of neglect. Behavioural neglect was considered as moderate to severe in $36 \%$ of cases. A factorial analysis revealed that paper and pencil tests were related to two underlying factors. Dissociations were found between extrapersonal neglect, personal neglect, anosognosia, and extinction. Anatomical analyses showed that neglect was more common and severe when the posterior association cortex was damaged.

Conclusions: The automatic rightward orientation bias is the most sensitive clinical measure of neglect. Behavioural assessment is more sensitive than any single paper and pencil test. The results also support the assumption that neglect is a heterogeneous disorder.
U nilateral neglect is a common feature and an important predictor of poor functional outcome after right hemisphere stroke. ${ }^{1-3}$ However, despite a large amount of research, there is still no consensus among clinicians regarding the methods of identifying neglect and monitoring changes after treatment. ${ }^{4-7}$ Clinical tests of neglect have infrequently been subjected to adequate validation and standardisation. Most of them lack normative data and tests sensitivity often remains unknown. In a recent systematic review of published reports, Bowen et al found that the frequency of occurrence of neglect in patients with right brain damage ranged from $13 \%$ to $82 \%$. The assessment method used was one of the main factors explaining the discrepancies between the different studies. Moreover, most commonly available clinical tests of spatial neglect do not take into account associated disorders, such as personal neglect, anosognosia, or sensory extinction, and their ecological validity remains questionable. ${ }^{7-10}$ Patients with normal performance on paper and pencil tests may demonstrate clinically significant neglect in everyday life. ${ }^{11}$

The aim of this study was to appraise the sensitivity of different assessment methods of spatial neglect after right hemisphere stroke. The assessment battery includes several paper and pencil tests, most of which were adapted from the existing literature, with their authors' permission. Related disorders such as anosognosia, extinction and personal neglect, were also investigated. In addition, a selected number of patients received a behavioural assessment, in order to compare conventional tests to real life functioning. Performance on clinical and paper and pencil tests was compared with that of a large control group, reported in detail elsewhere. ${ }^{12}$

\section{METHODS}

\section{Patients}

Two hundred and six consecutive patients $(60.7 \%$ men) suffering from a first ever unilateral right hemisphere stroke were consecutively included in 19 participating centres in France and Belgium. Mean (SD) age was 55.9 (15.3) years. Stroke was ischaemic in 135 patients $(65.5 \%)$ and haemorrhagic in $71(34.5 \%)$. Mean (SD) time since onset was 11.1 (13.8) weeks. Participating centres were mainly rehabilitation units, which explains that most patients were at a subacute phase. Educational level was assessed with a three level scale, similar to the control group. ${ }^{12}$ Most of the patients (53.2\%) had eight years or less of schooling, $22.7 \%$ had 9 to 12 years, and $24.1 \%$ had 13 years or more. Information about handedness was obtained through a standardised questionnaire providing a score ranging from 0 (left handed) to 100 (right handed). ${ }^{13}$ The majority of patients $(87.8 \%)$ were right handed (score of $80 / 100$ or more). The mean (SD) handedness score was 88.3 (20.6).

Motor impairments were assessed with a four level scale, ranging from 0 (no motor deficit) to 3 (severe hemiplegia). Seventeen patients $(9.1 \%)$ had no hemiplegia, $66(35.3 \%)$ had a mild hemiparesis, $64(34.2 \%)$ a moderate hemiplegia, and 40 $(21.4 \%)$ a severe hemiplegia (data were not available in 19 cases).

Patients were classified in four groups according to stroke localisation, as assessed with computed tomography or magnetic resonance imaging scans, or both: anterior (lesion limited to the prefrontal cortex and adjacent white matter, $\mathrm{n}=7$ ); posterior (lesion limited to the retrorolandic cortex, including parietal, but also temporal and/or occipital regions, 
$\mathrm{n}=29$ ); anteroposterior (lesion involving both prefrontal, rolandic, and posterior regions, $\mathrm{n}=92$ ); subcortical (lesion limited to subcortical areas, such as internal capsule, centrum semiovale, striatum, or thalamus, $\mathrm{n}=29$ ). Anatomical classification was done in each centre by examiners who were not informed of the results of neuropsychological evaluation. Anatomical data were not available in four patients.

\section{Procedure}

Testing conditions

The tasks were always given in the same order within one session of one hour or less, and in the same conditions as in control subjects. ${ }^{12}$ Patients were in a quiet environment, seated in a chair (not in their bed). The examiner sat in front of the patient and presented the test material centrally. Patients were asked not to move the material, nor their trunk, while performing the tasks. No time limit was given, and only one task was timed (the bells test), in order to provide a measure of speed of processing. At the end of each task, the examiner asked only once "are you finished ?", but gave no feedback to the patient. Assessments were conducted under the control of experienced examiners and all data were systematically reassessed centrally by two examiners (CS and ALD) of the coordinating centre. Homogeneity of testing conditions and of scoring was also checked by regular meetings with all participating centres.

\section{Preliminary assessment of related disorders \\ Awareness}

Awareness of motor and visual deficits was assessed using a methodology described by Bisiach et al. ${ }^{14}$ The examiner asked "Why are you now in the hospital? What are your current problems?". If the patient did not spontaneously mention a left sided problem, more direct questions were given. A four level scale was used, both for motor and visual impairments, ranging from 0: perfect awareness of the deficit, to 3: the patient never admitted having some impairment despite its demonstration by the examiner.

\section{Visual extinction and hemianopia}

The presence of extinction or of hemianopia was tested clinically by wiggling fingers for two seconds in one or both visual fields. Central gaze fixation was controlled by the examiner. Six trials were given, in a fixed pseudo-random sequence including four unilateral trials (two on each side), and two simultaneous bilateral trials. Extinction was considered as present when a patient failed at least once to report a contralesional stimulus during bilateral simultaneous presentation, while accurately detecting unilateral stimuli.

\section{Assessment of gaze orientation and personal neglect Gaze and head orientation}

Spontaneous gaze and head orientation was assessed with a four level scale ${ }^{15}$ ranging from 0: no deviation, to 3: permanent rightward deviation of gaze and head.

\section{Personal neglect}

Following Bisiach et al ${ }^{16}$ methodology, patients were asked to reach their left hand with the right hand, first with eyes open, then with eyes closed. A four level scale was used, ranging from 0: normal performance, to 3: no attempt to reach the target.

\section{Paper and pencil tests of extrapersonal neglect}

The following tests were selected because they had previously been found sensitive to the presence of unilateral neglect, and because they are easy to perform and to score in a clinical setting.

\section{The bells test ${ }^{17}$}

Subjects were asked to circle 35 targets (black ink drawings of bells), presented on a horizontal $21 \times 29.7 \mathrm{~cm}$ (A4) paper sheet, along with 280 distractors. Targets and distractors were presented in a pseudo-random array. They were equally distributed in seven columns (three on the left side, three on the right side, and one in the middle). The following variables were used: the total number of omissions $(/ 35)$, the difference between left sided and right sided omissions, and the subject's starting point (spatial location of the first circled target). The starting point was recorded to provide an estimate of the scanning strategy. Each column was attributed a number ranging from 1 to 7 (left to right), and the starting point was operationally defined as the number of the column including the first circled bell. The time taken to complete the task was also recorded.

Figure copying 1819

Subjects were asked to copy on a horizontal A4 sheet a drawing including (from the left to the right) a tree, a fence, a house with a left sided chimney, and a second tree. Following $\operatorname{Ogden}^{18}$, a five level scale was used, ranging from 0 (no omission) to 4 (omission of the left tree and of at least the left part of another item).

\section{Clock drawing}

Patients were required to place the 12 hours in a circle drawn by the examiner. A three level scale was used: 0: normal performance; 1: omission or rightward displacement of a part of the five left sided hours; 2 : omission or rightward displacement of all left sided hours.

\section{Line bisection}

Patients were asked to mark the middle of four lines of two different length (two $5 \mathrm{~cm}$ and two $20 \mathrm{~cm}$ ). The lines, of $1 \mathrm{~mm}$ width, centred on an A4 horizontal sheet, were presented separately. Deviation from the true middle was measured in $\mathrm{mm}$, positively for rightward deviations, negatively for leftward deviations.

\section{Overlapping figures test $t^{2}$}

One practice and five test stimuli were presented one at a time, each bearing five overlapping figures on a vertical A4 sheet. Each pattern consisted of two figures overlapping on the right and two on the left side of the card, all of them overlapping a fifth centrally located figure. Patients were not informed of the number of figures in each stimulus, and were asked to name all the figures they could detect. Two variables were used: the total number of omitted figures, and the difference between left sided and right sided omissions.

Reading ${ }^{21}$

Patients were asked to read a short text, horizontally printed on an A4 sheet. The text included 12 lines, but the patients were stopped after reading the fifth line. Again, two variables were used: the total number of words omitted, and the difference between left sided and right sided omissions.

\section{Writing}

This test was performed in standard writing conditions, using an A4 vertical sheet. Patients were asked to write, on three separate lines, their first and last names, address, and profession (or the current date if they had no profession). The score was the maximal left margin width (in $\mathrm{cm}$ ).

\section{Behavioural assessment of neglect and anosognosia}

In two participating centres, a standardised behavioural assessment of unilateral neglect and anosognosia in daily living activities was performed, using the Catherine Bergego Scale. ${ }^{22-24}$ Previous studies found that the scale had a good inter-rater reliability and concurrent validity, was more sensitive to neglect than paper and pencil tests, and was sensitive to change during rehabilitation. ${ }^{22-25}$ The scale was completed by an occupational therapist, based on a direct observation of the 
Table 1 Performance on paper and pencil tests

\begin{tabular}{|c|c|c|c|}
\hline Test variables & Mean (SD) & $\begin{array}{l}\text { Cut off } \\
\text { point }\end{array}$ & $\begin{array}{l}\% \\
\text { Beyond } \\
\text { cut off }\end{array}$ \\
\hline \multicolumn{4}{|l|}{ Bells test $(n=206)$} \\
\hline Omissions (total number) & $8.4(9.4)$ & $>6$ & 41.3 \\
\hline Omissions (left minus right) & $3.1(4.4)$ & $>2$ & 44.9 \\
\hline Starting point & $4.6(2.4)$ & $>5$ & 50.5 \\
\hline Figure coying $(n=205)$ & $1.2(1.6)$ & $>0$ & 42.7 \\
\hline $\begin{array}{l}\text { Clock drawing }(\mathrm{n}=205) \\
\text { Bisection }(\mathrm{mm})\end{array}$ & $0.4(0.6)$ & $>0$ & 27.8 \\
\hline $20 \mathrm{~cm}$ lines $(n=204)$ & $10.1(19.4)$ & $>6.5$ & 37.7 \\
\hline $5 \mathrm{~cm}$ lines $(n=200)$ & $0.6(3.7)$ & $>2.0$ & 19.0 \\
\hline \multicolumn{4}{|l|}{ Overlapping figures $(n=205)$} \\
\hline Omissions (total number) & $1.8(3.6)$ & $>0$ & 39.5 \\
\hline $\begin{array}{l}\text { Omissions (left minus right) } \\
\text { Text reading }(n=188)\end{array}$ & $0.8(1.9)$ & $>0$ & 30.7 \\
\hline Omissions (total number) & $11.9(25.3)$ & $>0$ & 46.8 \\
\hline Omissions (left minus right) & $5.6(11.4)$ & $>0$ & 41.2 \\
\hline $\begin{array}{l}\text { Writing (left margin, } \mathrm{cm}) \\
(\mathrm{n}=201)\end{array}$ & $6.8(5.0)$ & $>7.7$ & 34.3 \\
\hline
\end{tabular}

patient's behaviour in 10 everyday life situations, such as grooming, dressing, eating, or wheelchair driving. It was performed within the same week as conventional assessment, blindly to the results of paper and pencil tests. For each item, a four point scale was used, ranging from 0 (no neglect) to 3 (severe neglect). The total score ranged from 0 to 30. Anosognosia was assessed by comparing the examiner's score with the patient's rating on a self assessment version of the scale. ${ }^{22-24}$

\section{Data analysis}

Statistical analyses were performed using SPSS software (SPSS Inc, Chicago, Illinois, USA). The performance on paper and pencil tests was compared with that of control subjects from a previous study ( $\mathrm{n}=456$ to 576 , depending on the tests). ${ }^{12}$ For each variable, patients were considered as affected by unilateral neglect if they obtained a score poorer than the fifth percentile of the control group. For some tests that were performed without any error by all controls (figure copying, clock drawing, overlapping figures, and reading), any left sided omission was considered as an index of unilateral neglect. Neglect patients may present omissions not only in the left but also in the right hemispace. Consequently, two indices were used in the bells test, the overlapping figures and the reading tests: the total number of omissions, that gives an indication of overall severity of neglect, and a laterality index that is, left minus right omissions.

\section{RESULTS}

Preliminary assessment of related disorders

Seventeen per cent of patients had anosognosia for hemiplegia, and $46 \%$ for visual impairments. Extinction and hemianopia were tested in 186 patients. Sixty one $(32.8 \%)$ had a left hemianopia, and $36(19.3 \%)$ a left visual extinction without hemianopia.

\section{Assessment of gaze orientation and personal neglect}

A rightward gaze or head deviation was found in 32\% of patients. Personal neglect was found in $16 \%$ of cases with eyes open and $13 \%$ with eyes closed.

\section{Paper and pencil tests of extrapersonal neglect}

Test sensitivity was greatly variable, ranging from $19.0 \%$ to $50.5 \%\left(\chi^{2}=35.9, \mathrm{df}=11, \mathrm{p}=0.0002\right)$ (table 1). The whole battery was more sensitive than any single test alone, as 177 patients $(85.9 \%)$ demonstrated neglect on at least one measure. The most sensitive individual variable was the starting point in the bells test, which was located in $50.5 \%$ of cases in one of the two last right sided columns. Then, the decreasing order of sensitivity was the following: reading test (total number of omissions), bells test (difference between left and right omissions), figure copying, bells test (total number of omissions), reading (difference between left and right omissions), overlapping figures (total number of omissions), line bisection $(20 \mathrm{~cm})$, writing, overlapping figures (difference between left and right omissions), clock drawing, and line bisection $(5 \mathrm{~cm})$. In the line bisection task, a paradoxical leftward deviation was found in 78 patients $(39.0 \%)$ with $5 \mathrm{~cm}$ lines and in 50 patients $(24.5 \%)$ with $20 \mathrm{~cm}$ lines. The completion time of the bells test was slowed in $52.5 \%$ of cases, but poorly correlated with accuracy of performance $(r<0.16)$.

To assess the relations between the different tests, a correlation matrix was calculated for the 12 paper and pencil measures (table 2). Because of the large number of comparisons, the significance level was set at $p=0.0001$. The great majority of correlation coefficients (57 of 66 -that is, $86.3 \%)$ was positive and significant, and 23 (34.8\%) had a value of 0.50 or more. Most non-significant correlations involved short lines bisection.

Pearson correlation coefficients were also computed between paper and pencil tests and other clinical data, with again a significance level at 0.0001 . There were positive but moderate significant correlations with personal neglect and anosognosia for motor and visual impairments $(r<0.36)$. Stronger correlations were found with gaze deviation ( $r$ ranging from 0.31 to 0.51 ). Moderate significant correlations were found with motor impairments, particularly for the bells test, figure drawing, and writing ( $r$ ranging from 0.28 to 0.38 ).

Table 2 Correlation matrix of paper and pencil tests. Significant correlations $(p<0.0001)$ are shown in bold

\begin{tabular}{|c|c|c|c|c|c|c|c|c|c|c|c|}
\hline Test & 1 & 2 & 3 & 4 & 5 & 6 & 7 & 8 & 9 & 10 & 11 \\
\hline \multicolumn{12}{|l|}{ Bells test } \\
\hline \multicolumn{12}{|l|}{1 Omissions (total number) } \\
\hline 2 Omissions (left minus right) & 0.61 & & & & & & & & & & \\
\hline 3 Starting point & 0.44 & 0.32 & & & & & & & & & \\
\hline 4 Figure copying & 0.66 & 0.44 & 0.29 & & & & & & & & \\
\hline 5 Clock drawing & 0.39 & 0.26 & 0.18 & 0.35 & & & & & & & \\
\hline \multicolumn{12}{|l|}{ Bisection } \\
\hline $620 \mathrm{~cm}$ lines & 0.62 & 0.26 & 0.33 & 0.49 & 0.24 & & & & & & \\
\hline $75 \mathrm{~cm}$ lines & 0.19 & 0.13 & 0.15 & 0.10 & 0.18 & 0.49 & & & & & \\
\hline \multicolumn{12}{|l|}{ Overlapping figures } \\
\hline 8 Omissions (total number) & 0.72 & 0.19 & 0.31 & 0.54 & 0.41 & 0.74 & 0.31 & & & & \\
\hline $\begin{array}{l}9 \text { Omissions (left minus right) } \\
\text { Reading }\end{array}$ & 0.65 & 0.26 & 0.29 & 0.48 & 0.42 & 0.49 & 0.23 & 0.72 & & & \\
\hline 10 Omissions (total number) & 0.65 & 0.29 & 0.29 & 0.49 & 0.38 & 0.70 & 0.26 & 0.78 & 0.61 & & \\
\hline 11 Omissions (left minus right) & 0.57 & 0.40 & 0.27 & 0.51 & 0.29 & 0.58 & 0.15 & 0.56 & 0.49 & 0.82 & \\
\hline 12 Writing (left margin) & 0.61 & 0.33 & 0.39 & 0.53 & 0.30 & 0.53 & 0.13 & 0.57 & 0.44 & 0.50 & 0.52 \\
\hline
\end{tabular}


Table 3 Factor analysis of paper and pencil measures. Maximum likelihood extraction with oblimin rotation

\begin{tabular}{lll}
\hline & Factor 1 & Factor 2 \\
\hline Bells test & & \\
Omissions (total number) & 0.27 & $\mathbf{0 . 7 3}$ \\
Omissions (left minus right) & -0.18 & $\mathbf{0 . 9 0}$ \\
Starting point & 0.01 & $\mathbf{0 . 4 2}$ \\
Figure copying & 0.13 & $\mathbf{0 . 5 9}$ \\
Clock drawing & $\mathbf{0 . 4 3}$ & 0.09 \\
Bisection & & \\
$20 \mathrm{~cm}$ lines & $\mathbf{0 . 5 0}$ & 0.25 \\
$5 \mathrm{~cm}$ lines & $\mathbf{0 . 4 7}$ & -0.12 \\
Overlapping figures & & \\
Omissions (total number) & $\mathbf{0 . 9 6}$ & 0.01 \\
Omissions (left minus right) & $\mathbf{0 . 7 7}$ & 0.09 \\
Reading & $\mathbf{0 . 6 5}$ & 0.26 \\
Omissions (total number) & $\mathbf{0 . 4 1}$ & $\mathbf{0 . 4 0}$ \\
Omissions (left minus right) & 0.24 & $\mathbf{0 . 4 3}$ \\
Writing (left margin) & \\
\hline Loadings of 0.4 or more are shown in bold. & \\
\hline
\end{tabular}

There was no significant correlation with time since stroke onset or handedness. A trend was found for weak to moderate significant negative correlations with educational level and positive correlations with age $(r<0.32)$, suggesting that lower educational level and older age could be associated with poorer performance.

The relations between neglect and hemianopia or extinction were also assessed, and revealed double dissociations between both disorders. Indeed, two patients with hemianopia and three patients with extinction did not show neglect on any test, and on the other hand, 68 patients who demonstrated neglect on at least one measure had neither hemianopia nor extinction.

To assess the internal structure of the battery, a factorial analysis was computed, using maximum likelihood extraction with oblimin rotation. The best result disclosed two factors (eigenvalue $=5.7$ and 1.3 ) accounting for $51.6 \%$ of the total variance. Most items ( 11 of 12) were strongly associated with only one factor (table 3$)$. The first factor $(42.9 \%$ of total variance) included clock drawing, line bisection, and the overlapping figures test, while the second factor $18.7 \%$ of total variance) included the bells test, figure copying, and writing. Only the reading test loaded significantly on the two factors.

\section{Behavioural assessment of neglect and anosognosia}

Behavioural assessment was completed in 69 patients in two participating centres. The performance of these patients on conventional tests did not significantly differ from patients who did not receive the behavioural assessment. The most sensitive items of the scale were neglect of left limbs, left sided collisions, and neglect in dressing (table 4). Neglect was found on at least 1 of the 10 items in $76.8 \%$ of cases. This was not statistically different from the sensitivity of the whole paper and pencil battery $\left(\chi^{2}\right.$ test $\left.=2.7, \mathrm{df}=1, \mathrm{p}>0.1\right)$. Arbitrary cut off points were drawn in the total score to distinguish four levels of impairment. Behavioural neglect was absent (total score $=0$ ) in 16 patients $(23.2 \%)$, mild (total score: 1 to 10 ) in 28 patients $(40.6 \%)$, moderate (total score: 11 to 20 ) in 13 patients $(18.8 \%)$, and severe (total score: 21 to 30 ) in 12 patients $(17.4 \%)$.

Behavioural assessment correlated significantly with most paper and pencil tests, except for short line bisection (table 5). The strongest correlation concerned the total number of omissions on the bells test. However, individual analysis revealed that on one given test, dissociations may occur between conventional and behavioural assessment. For example, six patients performing within the normal range on the bells test showed a moderate to severe neglect on the Catherine Bergego Scale.
Table 4 Catherine Bergego Scale. Mean (SD) scores (range: 0-3), and percentage of patients with neglect (score $>0$ ) on each item of the scale and on the total score

\begin{tabular}{lcc}
\hline & Mean (SD) & $\begin{array}{l}\text { \% With } \\
\text { neglect }\end{array}$ \\
\hline Grooming & $0.70(0.94)$ & 43.33 \\
Dressing & $1.15(1.17)$ & 57.89 \\
Eating & $0.76(1.04)$ & 41.27 \\
Mouth cleaning & $0.65(1.05)$ & 32.81 \\
Gaze orientation & $1.07(1.11)$ & 56.25 \\
Knowledge of left limbs & $1.27(1.05)$ & 68.25 \\
Auditory attention & $0.72(0.98)$ & 39.06 \\
Moving (collisions) & $1.20(1.17)$ & 59.32 \\
Spatial orientation & $0.86(1.11)$ & 45.00 \\
Finding personal belongings & $1.04(1.20)$ & 50.00 \\
Total score (/30; $\mathrm{n}=69)$ & $9.37(9.04)$ & 76.81 \\
Self assessment $(/ 30 ; \mathrm{n}=67)$ & $5.30(5.20)$ & \\
\hline
\end{tabular}

Table 5 Pearson correlation coefficients between the total score at the Catherine Bergego Scale and conventional tests

\begin{tabular}{lll}
\hline Test & $r$ & $\mathrm{p}$ \\
\hline Bells test & & \\
Omissions (total number) & 0.77 & $<0.0001$ \\
Omissions (left minus right) & 0.57 & $<0.0001$ \\
Starting point & 0.62 & $<0.0001$ \\
Figure copying & 0.66 & $<0.0001$ \\
Clock drawing & 0.55 & $<0.0001$ \\
Bisection & 0.49 & $<0.0001$ \\
20 cm lines & 0.16 & 0.19 \\
5 cm lines & & \\
Overlapping figures & 0.65 & $<0.0001$ \\
Omissions (total number) & 0.56 & $<0.0001$ \\
Omissions (left minus right) & & \\
Reading & 0.53 & $<0.0001$ \\
Omissions (total number) & 0.57 & $<0.0001$ \\
Omissions (left minus right) & 0.62 & $<0.0001$ \\
Writing (left margin) & \multicolumn{3}{l}{} \\
\hline & & \\
\end{tabular}

To further investigate the relations between conventional and behavioural assessment, a stepwise multiple regression analysis was performed, with the total score on the Catherine Bergego Scale as dependent variable, and paper and pencil measures as explicative variables. Four variables, from three tasks, were found to significantly enter the regression equation $\left(r^{2}=0.79, F(4,57)=54.2, \mathrm{p}<0.00001\right)$ : the total number of omissions and the starting point in the bells test, and performance in figure copying and clock drawing (table 6 ). These three tasks in combination revealed neglect in 148 patients (71.84\%), and missed only 29 neglect patients $(16.38 \%)$, most of whom had a mild neglect.

Anosognosia for behavioural neglect was operationally assessed as the difference between the examiner's and the patient's self assessment scores on the Catherine Bergego Scale. Self assessment was significantly lower than the examiner's score (table 4) $(t(66)=-4.4, \mathrm{p}<0.0001)$. The difference was of 5 or more in 25 patients (37.3\%). Anosognosia for behavioural neglect correlated significantly, although moderately, with anosognosia for motor and visual impairment $(r=0.29$ and 0.37 respectively, $\mathrm{p}<0.05)$, but correlated strongly with neglect severity, as assessed with the Catherine Bergego Scale $(r=0.82, \mathrm{p}<0.0001)$, or with paper and pencil tests $(r$ ranging from 0.47 to $0.70, p<0.0001$ ), except for short line bisection. However, individual analysis revealed dissociations between anosognosia and neglect, some patients with moderately severe neglect obtaining anosognosia scores close to 0 . 
Table 6 Stepwise multiple regression analysis with the score at the Catherine Bergego Scale as dependent variable, and 12 paper and pencil measures as explicative variable

\begin{tabular}{llll}
\hline & Coefficient & $\begin{array}{l}\text { Standard } \\
\text { error }\end{array}$ & $\begin{array}{l}\text { Standardised } \\
\text { coefficient }(\beta)\end{array}$ \\
\hline $\begin{array}{l}\text { Bells test, total } \\
\text { omissions }\end{array}$ & 0.36 & 0.08 & 0.37 \\
Bells test, starting point & 1.25 & 0.24 & 0.34 \\
Figure drawing & 1.22 & 0.46 & 0.21 \\
Clock drawing & 3.59 & 0.90 & 0.26 \\
(constant) & -2.27 & 1.07 & \\
\hline
\end{tabular}

Four variables entered the final equation (standardised residuals: range: -4.1 to 2.3 , mean $=0.09, \mathrm{SD}=1.23$ )

\section{Anatomical-clinical correlations}

Performance on clinical tests was compared in the four groups as defined by stroke localisation by means of separate one way analysis of variance with one between subject factor (anterior; posterior; anteroposterior; subcortical). To limit type I error on multiple comparisons, the significance level was set at 0.01 . No significant effect of localisation was found for the following variables: anosognosia for motor and visual impairment, gaze deviation, the bells tests, clock drawing, bisection of short lines, overlapping figures, reading and writing. A significant effect of localisation was found for personal neglect $(F(3,197)=5.69, \mathrm{p}<0.001)$, figure drawing $(F(3,197)=4.22$, $\mathrm{p}<0.01)$ and bisection of long lines $(F(3,197)=4.51, \mathrm{p}<0.01)$. Post hoc analyses using Sheffe's correction showed that this effect was related to poorer performance in patients with posterior lesions.

\section{DISCUSSION}

The main objective of this study was to assess the sensitivity of a comprehensive test battery of spatial neglect in subacute right hemisphere stroke patients. As could be expected, sensitivity greatly varied from one test to another, ranging from $19.0 \%$ to $50.5 \%$. More than $85 \%$ of patients presented with some degree of neglect on at least one test. According to the behavioural assessment, neglect was considered as clinically significant (moderate to severe) in $36.2 \%$ of cases.

The great majority of patients were in rehabilitation units. This may explain the high incidence of neglect, because patients with less severe strokes are less likely to be admitted to a rehabilitation clinic. Nevertheless, the incidence of neglect was slightly higher than that reported in previous studies. ${ }^{26-32}$ For example, Halligan et $a l^{26}$ reported that $48 \%$ of right hemisphere stroke patients in rehabilitation suffered from neglect. Zoccolotti et $a l^{27}$ found that estimates of the disorder in rehabilitation patients varied with the test used from $26.7 \%$ to $52.0 \%$, but only $20 \%$ of patients had very severe neglect on the basis of overall clinical judgement. A higher incidence (75\%) was reported by Stone $e t \mathrm{al}^{29}$ in non-selected right hemisphere stroke patient three months after stroke.

In accordance with previous findings, ${ }^{23}$ the most sensitive tests were the bells tests and the reading test. These tests both include a strong visual component, which has been suggested to exacerbate neglect. ${ }^{33}$ Cancellation tasks are the most widely used tests for spatial neglect ${ }^{5}$, and many different versions have been proposed. The sensitivity increases when stimuli have a high density, are distributed in an unstructured pseudo-random array, or interspersed with distractors, ${ }^{47} 34-36$ all characteristics present in the bells test. The number of omissions is not the only measure that should be taken into account. ${ }^{17}$ In this study, the spatial location of the starting point spontaneously used by the subject was the most sensitive measure. While $80 \%$ of control subjects used a left to right strategy ${ }^{12}$, a majority of patients used a right sided starting point. This supports the assumption that the early automatic orientation of attention toward the ipsilesional half of space is a major component of unilateral neglect. ${ }^{2037}{ }^{38}$ Previous studies found that a rightward orientation bias was the only detectable residual impairment in patients who had apparently recovered from neglect. ${ }^{38} 39$

Text reading and figure copying were very sensitive. Reading has been less frequently used as a screening test for neglect. Previous studies using sentence reading, ${ }^{27}$ or menu or newspaper reading, ${ }^{8}$ found these latter tasks less sensitive than cancellation tasks. Drawings are the second most frequently used tests for spatial neglect. ${ }^{5}$ Halligan and Robertson $^{4}$ argued that copying, which relies heavily upon visual input, is more sensitive than drawing from memory. In this study, we used a scene including several separate components, which was assumed to be more sensitive than drawing one single item. ${ }^{18}$

Line bisection is also widely used. A length effect was found, in accordance with previous studies showing a linear increase in rightward displacement as a function of line length in most neglect patients. ${ }^{40}{ }^{41}$ Indeed, longer lines $(20 \mathrm{~cm})$ were nearly twice as sensitive than shorter $(5 \mathrm{~cm})$ ones. Bisection of short lines was the less sensitive test in the battery, and was the only paper and pencil test that did not correlate with behavioural neglect. A paradoxical leftward deviation (crossover effect) was found in some patients. In accordance with previous studies, ${ }^{41}{ }^{42}$ this phenomenon, of controversial mechanism, occurred more frequently with short lines. These results suggest that bisection of short lines should not be recommended as a screening test for neglect.

An important finding was that assessment across several different tests was more sensitive than any single test alone. Indeed, while the highest incidence of neglect found with any individual measure was of about $50 \%$, it increased up to more than $85 \%$ with the whole paper and pencil battery. This is in accordance with previous studies, ${ }^{182326}$ and suggests that a normal performance on one test alone is not sufficient to rule out the presence of neglect in a given patient.

A factorial analysis revealed two factors explaining performance on paper and pencil tests. In contrast, a previous study found only one underlying factor in a neglect assessment battery. ${ }^{26}$ These results suggest that the clinical tests that were used in this study may require different cognitive abilities and relate to different aspects of spatial neglect. However, the nature of the two factors remains questionable. Tests mainly associated with factor one (clock drawing, line bisection, identification of overlapping figures) require little motor activation towards the left hemispace, are relatively easy and may presumably be performed with little voluntary attentional control. On the other hand, tests associated with factor two (bells test, figure copying, writing) require a relatively complex and resource demanding visuo-motor behaviour in the left hemispace. In addition, few correlations were found in this study between extrapersonal and personal neglect. These findings support the frequently held assumption that unilateral neglect is not a unitary disorder, and that it may undercover dissociable clinical phenomena. ${ }^{164344}$ Whether these different clinical manifestations are related to distinct pathophysiological mechanisms or to a common underlying deficit remains controversial. ${ }^{45} 46$

Another aim of this study was to relate performance on conventional tests to behavioural neglect. Daily life frequently requires automatic orienting of attention, which is assumed to be impaired in neglect patients, while conventional assessment relies more on voluntary orienting, which recovers more rapidly. ${ }^{113}$ In this study, we used on a subset of patients the Catherine Bergego Scale, which had previously found to be valid, reliable, and sensitive to change. ${ }^{22-25}$ The sensitivity of the behavioural assessment was found higher than that of any single conventional test, and comparable to that of the whole 
paper and pencil battery. About $76 \%$ of patients demonstrated neglect on at least one item of the scale, and nearly half of them (36.2\% of the patient group) suffered from a moderate to severe behavioural neglect. A multiple regression analysis showed that four paper and pencil measures were able to significantly predict behavioural neglect, the total number of omissions and the starting point in the bells test, figure copying, and clock drawing. This suggests that, although clock drawing was not very sensitive, it should not be rejected, as it seems to add significant information regarding behavioural neglect. This finding may also have clinical implications, as it was found that if a shortened battery consisting of these three tests and four measures was used, it would have missed only $16.38 \%$ of neglect patients, most of whom had a mild neglect. This information might be useful for clinicians who cannot devote a large amount of time to the assessment of neglect.

In accordance with previous findings, ${ }^{47}$ double dissociations were found between neglect and visual sensory impairments (hemianopia or extinction). However, the data concerning sensory impairments should be taken with caution, as they were obtained through a simple clinical assessment, which is presumably less sensitive and reliable than an instrumental visual field assessment.

Anosognosia is a major concern in neglect patients, and has been found associated with poor recovery. ${ }^{314}$ The scale proposed by Bisiach et $a l^{14}$ investigates awareness of motor and visual impairments, while the Catherine Bergego Scale investigates awareness of behavioural neglect in daily living situations. Only few patients showed anosognosia for hemiplegia, but anosognosia for visual impairments and for behavioural neglect were more frequent. The three measures of anosognosia were significantly but weakly correlated one with each other $(r<0.40)$, suggesting that they may be related, at least in part, to distinct mechanisms. Anosognosia strongly correlated with neglect severity, but individual dissociations could be found, in accordance with previous studies. ${ }^{14} 49$

Speed of processing was measured in the bells test, and was found slowed in more than $50 \%$ of patients. This is in accordance with a large amount of data showing that patients with right brain damage suffer from mental slowness associated with an impairment of general (non-spatial) attentional capacity (alertness and vigilance)..$^{50}$ However, speed of processing was poorly correlated with accuracy of performance, suggesting an independence of spatial and non-spatial attentional deficits.

Analysis of performance in relation with localisation of lesion showed that both personal and extrapersonal neglect were significantly more severe in the group of patients with lesions located posterior to the rolandic sulcus. Although the results concerning the prefrontal group should be taken with caution, because of the small number of patients, these results are in accordance with previous anatomical studies of spatial neglect demonstrating that neglect occurs more frequently and is more severe in patients suffering from a parietal lesion as compared to patients with prefrontal or subcortical injury. ${ }^{13251}$

In summary, about $85 \%$ of subacute right hemisphere stroke patients presented at least some degree of unilateral neglect, which was considered as clinically significant (moderate to severe) in $36.2 \%$. The presence of neglect was task dependent. Tasks including a strong visual component were the most sensitive, and the automatic rightward orientation bias seemed to be the best indicator of unilateral neglect. However, several tests were more likely to uncover evidence of neglect than a single test. An important finding was that behavioural assessment of neglect in daily life was more sensitive than any other single measure of neglect. In addition, these data support the assumption of heterogeneity of neglect and the possible dissociation with anosognosia. Finally, it should be reminded that neglect is not an all or nothing phenomenon. One of us has recently reported that apparently recovered patients may demonstrate signs of spatial bias when confronted with a novel situation..$^{52}$ Non-specific factors, such as motivation, fatigue, emotional state, may also be of influence and should be taken into consideration in the assessment of neglect patients.

\section{ACKNOWLEDGEMENTS}

We are mostly grateful to E Bisiach, G Gainotti, L Gauthier, Y Joanette, J Ogden, and P van Eeckhout, for authorising us to include their tests in the battery.

We thank the following students for participating in data collection: $\mathrm{S}$ Ackermann, I Bruant, I Delattre, N Ferrin, C Festin, C Guillot, A Huguenin, K Kowalczuk, V Lagaron, I Legris, H Ougier, N Roux-Tetard, D Troudart-Lacombe, I Vincent, and C Yssembourg.

We are indebted to our colleagues who participated in data collection in the following centres: Hôpital Avicenne, Bobigny; Hôpital Bretonneau, Tours; Hôpital Fernand Widal, Paris; Hôpital Lariboisière, Paris; Hôpital de la Pitié-Salpêtrière, Paris; Hôpital Raymond Poincaré, Garches; Hôpital Roger Salengro, Lille; Hôpital Swynghedauw, Lille; Centre de Kerpape, Ploemeur; CNRF, Fraiture en Condroz (Belgium); Centre Neurologique William Lennox, Ottignies-Louvain-la-Neuve (Belgium); CRN, Cliniques Universitaires Saint-Luc, Bruxelles (Belgium); Centre de Rééducation Fonctionnelle L'Espoir, Lille; Centre de Réadaptation, Lay St Christophe; Centre de Rééducation Fonctionnelle, Salins-les-Bains; Centre de Rééducation et de Réadaptation Fonctionnelle, Trestel, Lannion; Centre de Rééducation et de Réadaptation pour Adultes, Coubert; Centre Thermal de Rééducation et de Réadaptation Fonctionnelle,Thues-les-Bains; Centre de la Tour de Gassies, Bruges (France).

\section{Authors' affiliations}

P Azouvi, C Samuel, A Louis-Dreyfus, G de Montety, S Olivier, Service de Rééducation Neurologique, Formation de Recherche Claude Bernard and Université René Descartes, Hôpital Raymond Poincaré, Garches, France

T Bernati, M Rousseaux, Service de Rééducation Neurologique, CHRU Lille, France

P Bartolomeo, INSERM U324, Centre Paul Broca, Paris, France

J-M Beis, Centre de Réadaptation, Lay-St-Christophe, France

S Chokron, Laboratoire de Psychologie Experimentale, CNRS UMR

5105, Grenoble, France

M Leclercq, Centre Neurologique William Lennox

Ottignies-Louvain-la-Neuve, Belgium

F Marchal, P Pradat-Diehl, Service de Rééducation, Hôpital de la Salpétrière, Paris, France

Y Martin, Centre de Rééducation l'Espoir, Lille-Hellemmes, France

D Perennou, Service de Rééducation Neurologique, Centre Medical, Le

Grau du Roi, France

C Prairial, CRN, Cliniques Universitaires Saint-Luc, Bruxelles, Belgium

G Rode, Service de Rééducation Neurologique, Hôpital Henry Gabrielle, Lyon, France

E Siéroff, Laboratoire de Psychologie Expérimentale, Université René

Descartes, Paris, France

L Wiart, Centre de la Tour de Gassies, Bruges, Belgium

\section{REFERENCES}

1 Heilman KM, Watson RT, Valenstein E. Neglect and related disorders. In: Heilman KM, Valenstein E, eds. Clinical neuropsychology. New York: Oxford University Press, 1993:279-336.

2 Denes G, Semenza C, Stoppa E, et al. Unilateral spatial neglect and recovery from hemiplegia. Brain 1982; 105:543-52.

3 Wade DT, Skilbeck CE, Langton Hewer R. Predicting Barthel ADL score at 6 months after an acute stroke. Arch Phys Med Rehabil $1983 ; 64: 24-8$

4 Halligan PW, Robertson IH. The assessment of unilateral neglect. In Crawford JR, Parker DM, McKinlay WW, eds. A handbook of neuropsychological assessment. Hove: Lawrence Erlbaum Associates, 1992:151-75.

5 Bowen A, McKenna K, Tallis RC. Reasons for the variability in the reported rate of occurrence of unilateral neglect after stroke. Stroke 1999;30: $1196-202$.

6 Stone SP, Patel P, Greenwood R, et al. Measuring visual neglect in acute stroke and predicting its recovery: the visual neglect recovery index. J Neurol Neurosurg Psychiatry 1992;55:431-6.

7 Robertson IH, Halligan PW. Spatial neglect: a clinical handbook for diagnosis and treatment. Hove, UK: Psychology Press, 1999.

8 Halligan PW, Cockburn J, Wilson B. The behavioural assessment of visual neglect. Neuropsychological Rehabilitation 1991;1:5-32. 
9 Zoccolotti P, Judica A. Functional evaluation of hemineglect by means of a semistructured scale: personal extrapersonal differentiation. Neuropsychological Rehabilitation 1991;1:33-44.

10 Towle D, Lincoln NB. Development of a questionnaire for detecting everyday problems in stroke patients with unilateral visual neglect. Clinical Rehabilitation 1991;5:135-40.

11 Seron X, Deloche G, Coyette F. A retrospective analysis of a single case neglect therapy: a point of theory. In: Seron X, Deloche G, eds Cognitive approaches in neuropsychological rehabilitation. Hillsdale: Lawrence Erlbaum Associates, 1989:289-316.

12 Rousseaux M, Beis JM, Pradat-Diehl P, et al. Présentation d'une batterie de dépistage de la négligence spatiale. Normes et effet de l'âge, du niveau d'éducation, du sexe, de la main et de la latéralité. Rev Neuro (Paris) 2001;157:1385-400.

13 Oldfield RC. The assessment and analysis of handedness: the Edinburgh inventory. Neuropsychologia 1971;9:97-113.

14 Bisiach E, Vallar G, Perani D, et al. Unawareness of disease following lesions of the right hemisphere: anosognosia for hemiplegia and anosognosia for hemianopia. Neuropsychologia 1986;24:471-82.

15 Rode G, Mauguière $F$, Fischer $C$, et al. Lésions hémisphériques droites et négligence unilatérale; La part de la déafférentation. Annales de Réadaptation et de Médecine Physique 1995;38:324.

16 Bisiach E, Perani D, Vallar G, et al. Unilateral neglect: personal and extrapersonal. Neuropsychologia 1986;24:759-67.

17 Gauthier L, Dehaut F, Joanette $Y$. The Bells test: A quantitative and qualitative test for visual neglect. International Journal of Clinical Neuropsychology 1989;11:49-54.

18 Ogden JA. Anterior-posterior interhemispheric differences in the loci of lesions producing visual hemineglect. Brain Cogn 1985;4:59-75.

19 Gainotti G, Messerli P, Tissot R. Qualitative analysis of unilateral spatial neglect in relation to laterality of cerebral lesions. J Neurol Neurosurg Psychiatry 1972;35:545-50.

20 Gainotti G, D'Erme P, Bartolomeo P. Early orientation of attention toward the half space ipsilateral to the lesion in patients with unilateral brain damage. J Neurol Neurosurg Psychiatry 1991;54:1082-9.

21 Van Eeckhout P, Sabadel J, Signoret JL, et al. Histoires insolites pour faire parler. Paris: MEDSI, 1982

22 Bergego C, Azouvi P, Samuel C, et al. Validation d'une échelle d'évaluation fonctionnelle de l'héminégligence dans la vie quotidienne: l'échelle CB. Annales de Réadaptation et de Médecine Physique 1995; $38: 183-9$.

23 Azouvi P, Marchal F, Samuel C, et al. Functional consequences and awareness of unilateral neglect: Study of an evaluation scale. Neuropsychological Rehabilitation 1996:6:133-50.

24 Azouvi P, Olivier S, de Montety G, et al. Behavioral assessment of unilateral neglect: Study of the psychometric properties of the Catherine Bergego Scale. Arch Phys Med Rehabil (in press)

25 Samuel C, Louis-Dreyfus A, Kaschel R, et al. Rehabilitation of very severe unilateral neglect by visuo-spatio-motor cueing: Two single-case studies. Neuropsychological Rehabilitation 2000;10:385-99.

26 Halligan PW, Marshall JC, Wade DT. Visuospatial neglect: Underlying factors and test sensitivity. Lancet 1989;ii:908-10

27 Zoccolotti $\mathbf{P}$, Antonucci $G$, Judica A, et al. Incidence and evolution of the hemineglect disorder in chronic patients with unilateral brain damage. Int J Neurosci 1989:47:209-16.

28 Hier DB, Mondlock J, Caplan LR. Behavioral abnormalities after right hemisphere stroke. Neurology 1983;33:337-44.

29 Stone SP, Wilson B, Wroot A, et al. The assessment of visuo-spatial neglect after acute stroke. J Neurol Neurosurg Psychiatry $1991 ; 54: 345-50$.
30 Wade DT, Wood VA, Langton Hewer R. Recovery of cognitive function soon after stroke: a study of visual neglect, attention span and verbal recall. J Neurol Neurosurg Psychiatry 1988; 51:10-13.

31 Pedersen PM, Jorgensen HS, Nakayama H, et al. Hemineglect in acute stroke. Incidence and prognostic implications. The Copenhagen stroke study. Am J Phys Med Rehabil 1997;76:122-7.

32 Leibovitch FS, Black SE, Caldwell CB, et al. Brain-behavior correlations in hemispatial neglect using CT and SPECT: the Sunnybrook Stroke Study. Neurology 1998;50:901-8

33 Bartolomeo P, Chokron S. Levels of impairment in unilateral neglect. In: Boller F, Grafman J, eds. In Behrmann M, ed. Handbook of neuropsychology, 2nd edn, vol 4: Disorders of visual behavior. Amsterdam: Elsevier Science, 2001:67-98.

34 Albert M. A simple test of visual neglect. Neurology 1973;23:658-64.

35 Diller L, Weinberg J. Hemi-inattention in rehabilitation: the evolution of a rational remediation program. In: Weinstein EA, Friedland RP, eds. Advances in neurology. New York: Raven Press, 1977:63-82.

36 Mesulam MM. Principles of behavioral neurology. Philadephia: F A Davies, 1985

37 De Renzi E, Gentilini M, Faglioni P, et al. Attentional shift towards the rightmost stimuli in patients with left visual neglect. Cortex 1989;25:231-7.

38 Mattingley JB, Bradshaw JL, Brashaw JA, et al. Residual rightward attentional bias after apparent recovery from right hemisphere damage: implications for a multicomponent model of neglect. J Neurol Neurosurg Psychiatry 1994;57:597-604

39 Campbell DC, Oxbury JM. Recovery from unilateral visuo-spatial neglect? Cortex 1976;12:303-12.

40 Bisiach E, Bulgarelli $C$, Sterzi $C$, et al. Line bisection and cognitive plasticity of unilateral neglect of space. Brain Cogn 1983;2:32-8.

41 Halligan PW, Marshall JC. How long is a piece of string? A study of line bisection in a case of visual neglect. Cortex 1988;24:321-8.

42 Marshall JC, Halligan PW. Line bisection in a case of visual neglect; psychophysical studies with implications for theory. Cognitive Neuropsychology 1990; 7:107-30.

43 Heilman KM, Bowers D, Coslett HB, et al. Directional hypokinesia: prolonged reaction times for leftwards movements in patients with righ hemisphere lesions and neglect. Neurology 1985;35:855-60.

44 Halligan PW, Marshall JC. Left neglect for near but not for far space in man. Nature 1991;350:498-500.

45 Vallar G. Left spatial hemineglect: An unmanageable explosion of dissociations? No. Neuropsychological Rehabilitation 1994;4:209-12.

46 Halligan PW, Marshall JC. Left visuo-spatial neglect: A meaningless entity? Cortex 1992;28:525-35.

47 Cocchini G, Cubelli R, Della Sala S, et al. Neglect without extinction. Cortex 1999:35:285-313.

48 Gialanella B, Mattioli F. Anosognosia and extrapersonal neglect as predictors of functional recovery following right hemisphere stroke. Neuropsychological Rehabilitation 1992;2:169-78.

49 Dauriac-Le Masson V, Mailhan L, Louis-Dreyfus A, et al. Double dissociation entre négligence unilatérale gauche et anosognosie. Rev Neurol (Paris) 2002;158:427-30.

50 Robertson IH. The relationship between lateralised and non-lateralised attentional deficits in unilateral neglect. In: Robertson IH, Marshall JC, eds. Unilateral neglect: clinical and experimental studies. Hove: Lawrence Erlbaum Associates, 1993:257-75.

51 Vallar G, Perani D. The anatomy of unilateral neglect after right hemisphere stroke lesions: A clinical CT/scan correlation study in man Neuropsychologia 1986;24:609-22.

52 Bartolomeo P. The novelty effect in recovered hemineglect. Cortex 1997; 33:323-32 